\title{
The National Bureau of Standards Becomes The National Institute of Standards and Technology
}

On August 23, 1988 President Reagan signed the Omnibus Trade and Competitiveness Act and changed the name of the National Bureau of Standards to the National Institute of Standards and Technology (NIST). Under a section of this new law known as the "Technology Competitiveness Act," several new assignments designed to boost U.S. industry in the world marketplace are added to the traditional functions of NIST.

NIST will continue to serve as the Nation's central laboratory for developing and disseminating measurement standards and scientific data for science, engineering, manufacturing, commerce, industry, and education. NIST will continue to provide a variety of services to the scientific and technical communities, including calibration services, standard reference data, and standard reference materials. These activities and the continuing research programs will continue to form the technical core of NIST.

New activities NIST has been assigned to develop are:

1. Create a series of Regional Centers for the Transfer of Manufacturing Technology that will be affiliated with non-profit institutions and organizations;

2. Develop a program to provide assistance and make Federal technology available to State and local technology programs and technology extension services;

3. Establish an Advanced Technology Program to encourage the commercialization of new high-technology products; and

4. Support a Department of Commerce Clearinghouse for State and Local Initiatives on Productivity, Technology, and Innovation to provide technical and analytical help to State and local officials making decisions on technology policy.

In keeping with the new name of our laboratories, we have changed the name of this journal to:

Journal of Research of the National Institute of Standards and Technology

Under its new name, this journal will continue its policy of presenting technical articles and news items of particular interest to scientists, technicians, and engineers interested in measurement methodology and analyses.

Karl G. Kessler Chief Editor 